\title{
Mobilizar o mundo: O povo da mercadoria partindo das perspectivas de Bruno Latour e Davi Kopenawa Yanomami
}

Claudio Hunger

Universität Zürich

-claudio.hunger@bluewin.ch

Dol https://doi.org/10.34913/

journals/lingualugar.2020.e420 
A queda do céu apresenta uma sociedade ocidental cujos membros são prisioneiros de uma paixão obsessiva pelos objetos. Os brancos, ou usando a palavra yanomami, os napë, sonham, segundo Davi Kopenawa Yanomami, com objetos e acumulam-nos, nem que seja para tê-los armazenados em casa. A visão sobre os napë, que Kopenawa desenvolve no seu livro, propõe uma sociedade ocidental caraterizada por uma relação patológica com os objetos. Esta proposta, expressa na denominação povo da mercadoria, dialoga com a perspectiva de Bruno Latour, segundo a qual os objetos são de primordial importância para a constituição da sociedade ocidental. Com o presente ensaio, que se baseia nos dois pensadores acima mencionados, procuro atingir três objetivos. Primeiro: dar uma ideia da ameaça que o Ocidente representa para os yanomami. Segundo: mostrar que esta ameaça se deve antes de mais à relação que o Ocidente mantém com os objetos. Terceiro: assinalar que A queda do céu se debruça tanto sobre os yanomami quanto sobre os napë.

Palavras-chave: Objetos; coletivos; Ocidente; Davi Kopenawa Yanomami; Bruno Latour.

La chute du ciel représente une société occidentale dont les membres sont amoureux ou plutôt obsédés par les objets. Les blancs, en terme yanomami, les napë, rêvent, selon Davi Kopenawa Yanomami, d'objets et les accumulent, peu importe s'ils en ont besoin ou pas. La perspective sur les napë que Kopenawa développe dans son livre, postule que 
la société occidentale se caractérise sur la base de sa relation avec les objets. Cette proposition, reflétée dans la désignation povo da mercadoria, dialogue avec la perspective de Bruno Latour, selon qui les objets sont d'une importance primordiale pour la constitution de la société occidentale. Je poursuis par le présent essai, qui s'appuie sur les deux auteurs mentionnés, trois objectifs. Premièrement: donner une idée de la menace que l'occident représente pour les Yanomami. Deuxièmement: montrer que cette menace est due surtout à la relation que l'occident tient avec les objets. Et troisièmement: signaler que La chute du ciel se réfère autant aux Yanomami qu'aux napë.

Mots-clefs: Objets; collectifs; Ouest; Davi Kopenawa Yanomami; Bruno Latour.

Para começar este ensaio, gostaria de mostrar que alguns dos estudos antropológicos mais conhecidos sobre os yanomami são muito depreciativos. Estes estudos usaram os imaginários sobre o selvagem com o objetivo de evidenciar a alteridade dos yanomami. A separação entre um eu civilizado e um outro selvagem é, com frequência, um ato significativo, pois as antropologias têm a capacidade de marcar as maneiras como uma sociedade pensa e fala sobre os grupos que os antropólogos descrevem. Essas maneiras, esses discursos, por sua vez, podem influenciar os direitos que são concedidos aos yanomami, ou seja, o grau de violência utilizada contra eles. Partindo das ideias de Bruno Latour, pretendo mostrar que a sociedade é um coletivo de entidades humanas e não humanas que, no seu conjunto, marcam o social. O que sobretudo distingue os napë dos yanomami é a quantidade e a qualidade dos objetos que os seus coletivos mobilizam. A constituição do coletivo napë promove a integração incessante de objetos, ou seja, a expansão do sistema capitalista. Deste processo constitutivo deriva o perigo que os napë representam para os yanomami. Tentando desacelerar o empreendimento capitalista e querendo proteger o seu povo, Kopenawa dirige o seu texto à atenção dos napë. Em A queda do céu, Kopenawa valoriza o seu povo dando um testemunho da riqueza cultural yanomami. Ao mesmo tempo, descreve a convivência destes com o coletivo ocidental, escrevendo assim uma antropologia yanomami sobre os napë. 
O discurso antropológico sobre os yanomami foi marcado, de forma duradoura, por dois tipos de relatos anteriores e contrapostos. Ambos se valeram dos estereótipos que circulavam de uma forma ou de outra desde a Idade Clássica e que, a partir do final da Idade Média, se cristalizaram em dois imaginários proeminentes sobre o homem selvagem. Um desses imaginários, partia da ideia de um bom selvagem em perfeito estado natural, de certo modo edénico. Os mais conhecidos representantes deste tipo de discurso, criticamente posicionados em relação às suas próprias sociedades, foram Jean-Jacques Rousseau, John Locke e Charles-Louis de Montesquieu. O outro imaginário baseava-se na ideia de um selvagem habitando uma natureza hostil, marcada pela luta e pelo sofrimento. Esse selvagem imaginado apareceu como antípoda e construção ex-negativa de um outro ser: o ser civilizado que aceitava a sociedade com as suas normas e que vivia num estado supostamente desejável para a humanidade. Os representantes mais proeminentes desta tradição de pensamento foram Niccolò Machiavelli e Thomas Hobbes (White, 1978, p. 173).

Quando Bruce Albert iniciou o seu trabalho de campo, o discurso antropológico sobre os yanomami era ainda pouco desenvolvido e padecia de uma certa superficialidade quanto à descrição cosmológica e social dessa cultura. Os estudos mais conhecidos daquela época foram os trabalhos de Jacques Lizot e Napoléon Chagnon. ${ }^{1}$ Segundo Albert, esses dois estudos não são

1 Veja-se por exemplo: Chagnon, 1968. satisfatórios, já que ambos adotaram conceitos sociológicos de povos africanos transferindo-os para os yanomami. Ambos os autores demonstraram a mesma falta de subtileza ao reproduzir (parcialmente) os discursos descritos anteriormente. Enquanto Lizot mantinha a tradição do bom selvagem e construía um yanomami idílico, Chagnon retratava um yanomami violento e selvagem, no pior sentido do termo (Kopenawa e Albert, 2015, pp. 516-517).

Embora os escritos destes autores se assemelhem parcialmente nas suas insuficiências científicas, distinguem-se fundamentalmente pelo impacto que tiveram no discurso popular e na atitude que adotaram em relação aos yanomami. A partir dos trabalhos de Chagnon, cujo livro Yanomamö: the fierce people vendeu mais de três milhões de exemplares, estabeleceu-se um discurso mediático que ajudou os yanomami a obter uma duvidosa e inesperada fama internacional. Por força de uma avalanche de expressões mediáticas, instalou-se uma imagem racista dos yanomami 
como um povo selvagem, violento e sujo, imerso num estado natural de tipo hobbesiano. Esta representação profundamente ofensiva foi dominante até ao final dos anos 80 (Kopenawa e Albert, 2015, pp. 516, 557-558). Infelizmente, é importante constatar que, até hoje, os yanomami não foram capazes de se livrar por completo dessa malícia intelectual e que, nos Estados Unidos da América, os livros de Chagnon ainda fazem parte do cânone do ensino universitário. Em 2013, Chagnon publicou o seu último livro que também foi traduzido em português e divulgado no Brasil (Chagnon, 2013). Entre outras ideias absurdas, esta obra apresenta os yanomami como um povo cuja meta absoluta seria a reprodução dos guerreiros que mais inimigos tivessem matado em combate (De Castro, 2015, pp. 25-26).

Avaliar o impacto que estas investigações etnocêntricas podem ter tido no pensamento e no discurso brasileiros sobre os yanomami seria uma tarefa extremamente difícil e está fora do escopo do presente ensaio. Porém, gostaria de demonstrar nas seguintes linhas que o discurso depreciativo sobre os yanomami é mais do que uma mera "conversa" inocente. Como Hayden White assinala, o conceito do homem selvagem tem - a partir da perspectiva dos civilizados - a função de "dignificar o seu modo específico de existência, contrastando-o com os outros homens, reais ou imaginários, que apenas diferem de si" (White, 1978, p. 152).

Através da construção de uma imagem dos yanomami como selvagens, também se foi construindo o seu antónimo - a sociedade ocidental, ou seja, o civilizado. ${ }^{2}$ Ao mesmo tempo que este discurso desvaloriza completamente o selvagem, venera o seu oposto e instala a superioridade discursiva do civilizado. A consequência dessa divisão entre selvagens e civilizados foi, entre muitas outras coisas, o duplo padrão moral que justificou as práticas violentas contra o outro, o yanomami. Agentes do mundo ocidental - no seu sentido mais amplo - serviram-se e ainda se servem da imagem dos yanomami desumanizados para justificarem a perpetração violenta dos seus interesses. Uma

$\mathbf{2}_{\mathrm{N}}$ ensaio civilizado e ocidental é usado para denominar a sociedade não indígena. Evidentemente, uma identidade como a sociedade ocidental é uma simplificação e redução da multiplicidade das diferenças que existem no seu seio. No entanto, a sociedade ocidental pode ser pensada como uma relação comunicativa e comercial com os seus centros e periferias. Esta definição apoiase no que Niklas Luhmann determina como Weltgesellschaft, veja-se: Luhmann, 1997. vez desumanizados os yanomami e, portanto, deslegitimados como donos das terras ou das suas próprias cosmologias, as possibilidades de apropriação parecem ter-se multiplicado para os ditos agentes. Esses atores, entre outros, foram e são - infelizmente a forma presente do verbo ainda é adequada - burocratas, políticos, militares, agentes da indústria mineira ou agrícola e missionários (De Castro, 2015, p. 25). O depoimento do general Gentil Nogueira Paes, no contexto das invasões 
militares ao território Waimiri-Atroari, na década de 1970, dá uma ideia de como a descrição de um outro violento o desvaloriza e é usada para legitimar a violência do agressor. O general declarou:

\begin{abstract}
A Estrada (BR-174) tem que ficar pronta, mesmo que para isto tenhamos que abrir fogo contra esses índios assassinos. Eles já nos desafiaram muito e estão atrapalhando nossos trabalhos. (...) [N]ão vai ser um grupo de índios assassinos que vai impedir o prosseguimento da obra (Nogueira Paes apud Carvalho, 1982, p. 74).
\end{abstract}

A formação de um pensamento anti-indígena e as estratégias de comunicação que preparam e legitimam a apropriação violenta do indígena também são observadas por Davi Kopenawa. Em Nova lorque, Kopenawa imagina como os antigos norte-americanos devem ter pensado sobre os nativos daquela época: "Vamos acabar com esses índios sujos e preguiçosos! Vamos tomar o lugar deles nesta terra! Seremos os verdadeiros americanos, porque somos brancos! Somos mesmo espertos, trabalhadores e poderosos!" (Kopewana, 2015, p. 433). Aqui Kopenawa descreve a egolatria dos brancos através do desprezo que cultivam em relação aos indígenas. Kopenawa entende com clareza a função destas estratégias comunicativas:

É com as mesmas palavras que os garimpeiros e os fazendeiros querem se livrar de nós no Brasil: "Os yanomami são apenas seres da floresta, não são humanos! Pouco importa que morram, eles são inúteis e nós vamos trabalhar de verdade no lugar deles!" (Kopewana, 2015, pp. 433-434).

Kopenawa revela a ligação entre o desprezo articulado contra os yanomami, a egolatria ocidental, e como esta estratégia comunicativa desumaniza e é utilizada para apropriar-se dos yanomami. Em outra ocasião, Kopenawa refere: "Só quer espalhar más palavras sobre nós porque precisa da ajuda delas para conseguir se apoderar de nossa terra" (Kopewana, 2015, p. 440). Tendo em conta o poder das palavras, torna-se evidente a falta de um discurso que valorize e, consequentemente, proteja os yanomami.

\title{
O povo da mercadoria segundo Bruno Latour
}

Segundo Bruno Latour, jamais fomos modernos porque, à partida, nunca deixámos de construir as nossas sociedades da mesma maneira que o fizeram as sociedades supostamente pré-modernas. A distinção que os modernos criaram entre as suas próprias sociedades e as sociedades pré-modernas nunca existiu de forma tão absoluta quanto os modernos 
costumavam imaginar. As nossas sociedades sempre foram um coletivo entre seres humanos e entidades não-humanas, ou seja, híbridos, que como um todo marcam e determinam o social. A rejeição do pressuposto desta grande diferença é o núcleo e o início de uma antropologia simétrica (Latour, 2008, pp. 129, 140, 152).

A diferença entre os dois tipos de coletivos reside, antes de mais, na quantidade de entidades não-humanas que se mobilizam e se integram nos respetivos coletivos, bem como nas propriedades que lhes são atribuídas (Latour, 2008, p. 142). Como os pré-modernos consideram permanentemente a relação entre natureza e cultura, são cautelosos em relação à incorporação do não-humano nos seus coletivos. Porque, uma vez integrados, os objetos convertem-se em híbridos - meio sujeitos e meio objetos - que, tal como denuncia a subjetividade que Latour Ihes atribui, desempenham um papel protagonista (Latour, 2008, p. 155). Os modernos, por outro lado, não acreditam que a ordem social corresponda à ordem natural. Deste pensamento moderno resulta uma despreocupação pelo efeito que as inovações, possibilitadas sobretudo pela ciência e pela tecnologia, exercem na ordem social e cósmica. Enquanto que os pré-modernos tendem a mobilizar sobretudo as representações simbólicas da natureza, os modernos mobilizam a própria natureza e numa escala quase ilimitada e ameaçadora para a vida no mundo. Latour sintetiza o pensamento e as práticas que possibilitam a edificação do coletivo moderno com as seguintes palavras: "Se (...) nossa Constituição permite tudo, o que há na verdade é a socialização acelerada dos não-humanos, sem no entanto permitir a estes que apareçam, em um momento qualquer, como elementos da 'sociedade real'" (Latour, 1994, p. 46-47). Graças à distinção entre o natural e o social, que posteriormente discutiremos com mais pormenores, os modernos deixaram de considerar a forma como os objetos marcam as relações sociais e mudam o coletivo. Foi com essa despreocupação, e por meio de certos tipos de híbridos, que os modernos começaram a sua longa história de expansão, ampliando o seu coletivo ao integrar cada vez mais híbridos e sujeitos (Latour, 2008, pp. $59,130,148)$. Hoje em dia, esse processo, a que chamamos crescimento, é institucionalizado como objetivo de quase todas as políticas nacionais: continuando a atar e reatar as relações sociais e - pensando no antropoceno $-{ }^{3}$ naturais.

\footnotetext{
3 Sobre o conceito antropoceno veja-se: Crutzen, 2006
} 


\section{Práticas de purificação que abrem caminho a uma hibridação descontrolada}

Os modernos constroem os seus coletivos com base em dois conjuntos de práticas. O primeiro conjunto encarrega-se de uma purificação intelectual, criando duas zonas ontológicas distintas e separadas por completo: uma zona humana e uma zona não-humana. O segundo conjunto, invisibilizado pelo primeiro, trata da produção de híbridos, isto é, entidades novas e não-humanas, que não são puramente naturais, nem puramente sociais ou culturais. Latour denomina essas práticas, exercidas sobretudo no campo da ciência e da tecnologia, como práticas de tradução (Latour, 2008, pp. 19, 28).

As práticas de purificação - símbolo da autopercepção dos modernos separam a força social ou cultural da força natural. Esta macrodistinção nomeia os dois campos (intelectualmente) separados onde se reúnem entidades bem conhecidas da tradição ocidental. No campo social, encontram-se entidades como o sujeito de direito, ou seja, os cidadãos, representados pelos seus porta-vozes políticos. No campo da força natural alinham-se os objetos silenciosos da ciência que são representados pelos cientistas, que dão voz a esses objetos e forças (Latour, 2008, pp. 42,55). O objetivo do processo de purificação é limpar o saber natural de qualquer influência humana, a fim de garantir que os resultados da pesquisa científica descrevam, segundo os modernos, a própria natureza. A força política, por outro lado, é pensada como uma construção humana e imanente: as vozes dos cidadãos autorizam o Leviatã, que fala e governa em nome dos seus representados. Deste pressuposto decorre a garantia de que a sociedade é construída pelos seus humanos e de que estes decidem o seu destino. Estas exigências de pureza exigem que os cientistas façam desaparecer os seus instrumentos, o laboratório e o lugar histórico dos humanos por trás da produção do saber. Após a execução destas práticas, que fazem desaparecer da vista todo o hibridismo humano/natural, resta um saber não produzido que simplesmente des-cobre os segredos da natureza (Latour, 2008, pp. 43-44, 49).

Por último, a constituição dos modernos requer a ausência de Deus do dualismo moderno, ou seja, tanto no âmbito natural como no âmbito cultural. Porém, de acordo com esta ordem, Deus não desaparece por completo. Ainda assume o papel de um Deus transcendente que não influencia os caprichos da natureza nem o curso dos eventos políticos, mas que continua disponível. No caso de conflitos entre os dois mundos, Deus pode ser evocado para assumir a função de tribunal arbitral (Latour, 2008, p. 47). 
A constituição moderna, com o seu foco intelectual na separação do humano do não-humano, tem como consequência a ausência de reflexão sobre o segundo conjunto de práticas. Por isso, as práticas de tradução, ou seja, de hibridização - práticas que são constitutivas de qualquer coletivo - ficam fora da atenção dos modernos. Como resultado, a natureza, apesar de ser considerada transcendente, é incessantemente mobilizada, incorporada e socializada a um nível sem precedentes. É transformada em fábricas, reconstruída em laboratórios, ou seja, integrada de mil maneiras no âmbito humano. Desta incorporação surgem novas entidades chamadas (seres) híbridos. Esta denominação enfatiza o seu estado de mistura entre o humano e natural. Por outro lado, com o predicado ser pronuncia-se o papel constitutivo para a ocorrência do social e natural (Latour, 2008, pp. 22, 43, 49, 52). Os princípios que as práticas de purificação estabeleceram - natureza transcendente, sociedade imanente - são novamente invertidos quando observamos o efeito que as práticas de tradução realmente têm no social. A ilusão dos modernos de uma sociedade guiada por um Leviatã que simplesmente traduz e executa a vontade dos cidadãos, começa a vacilar facilmente se nos concentrarmos nos híbridos. O laboratório, a bolsa de valores, o arquivo, as instituições científicas, etc. produzem híbridos que são tão constituintes e estabilizadores da ordem e do comportamento social que é impossível manter a ideia de uma sociedade como um simples produto da vontade dos seus sujeitos livres. Em vez disso, vemo-nos confrontados a uma sociedade que, em muitas ocasiões, parece superar e dominar os seus membros com lógicas quase absolutas, ou seja, transcendentes. Um bom exemplo disto é a bolsa de valores, onde um entrelaçado de humanos e híbridos determina um índice bolsista - outro híbrido - que, por sua vez, dita e define as relações (económicas) de grupos sociais inteiros. Seguindo estes pressupostos, não há sociedade moderna, pelo menos não na medida em que os modernos imaginam, que se construa politicamente. O papel que jogam os híbridos, o facto dos modernos não verem, não pensarem, e ainda menos controlarem a sua expansão e efeitos, tornam-no impossível. Os híbridos aparecem como o grande inconsciente que determina o curso do social e, considerando a intrusão de Gaia, ${ }^{\mathbf{4}}$ também do natural (Latour, 2008, pp. 52-53). Para finalizar, cito Latour, que sintetiza de forma concisa o poder moderno que se desenvolve a partir de uma constituição paradoxal: "Qual outra forma de estender os coletivos seria melhor do que juntar tanto a transcendência da natureza quanto a total liberdade

\footnotetext{
4 Sobre o perigo que representa a aparição de Gaia veja-se: Danowski, D. e De Castro, E. V. (2014). De modo geral, os autores compartilham a ideia de Bruno Latour e de Isabelle Stengers que abordam a intrusão de Gaia para descrever as futuras forças ambientais mais difíceis de convivência.
} 
humana, incorporando ao mesmo tempo a natureza e limitando de forma absoluta as margens de liberdade? Isto permite, na verdade, que se faça tudo e também o contrário" (Latour, 1994, p. 43).

Graças às ideias de Bruno Latour podemos cancelar a vigência das duas zonas ontológicas e começar a ver os híbridos que se alinham entre os dois polos já descartados. A sociedade não é uma comunidade de humanos, mas sim um coletivo que se constitui através da relação dos humanos com os híbridos. Estes últimos não deveriam ser negligenciados, uma vez que os efeitos decorrentes da sua produção e o papel que jogam para a interação e as práticas humanas traçam, simultaneamente, as formas da natureza e também o comportamento social (Latour, 2008, p. 143). Gostaria de concluir este capítulo com uma metáfora de Latour que desenha de maneira condensada o auto-engano em que os modernos caíram:

\begin{abstract}
Os descendentes de Hobbes não afirmam apenas que os homens criam sua própria sociedade aos murros, mas também que o Leviatã é durável e sólido, imenso e forte, que mobiliza o comércio, as invenções, as artes, e que o soberano tem em suas mãos a espada de aço temperado e o cetro de ouro. Apesar de sua construção humana, o Leviatã ultrapassa infinitamente o homem que o criou, pois mobiliza em seus poros, em seus vasos, em seus tecidos as coisas inumeráveis que lhe dão sua consistência e duração. E no entanto, apesar desta duração obtida pela mobilização das coisas e revelada pelo trabalho da mediação, somos nós e somente nós que o constituímos unicamente pela força do nosso cálculo, nós, pobres cidadãos nus e desarmados - conforme é demonstrado pelo trabalho de purificação (Latour, 1994, pp. 36-37).
\end{abstract}

Estas palavras indicam que o poder político que emite o Leviatã não é um simples derivado da vontade e do trabalho dos cidadãos que, segundo a teoria de Thomas Hobbes (Hobbes, 1990) são quem o constroem. Em vez disso, o seu poder baseia-se nos objetos, ou seja, nos híbridos, que sustentam esse mandante armado. Por meio dos objetos, o Leviatã é duradouro e sólido, e supera os humanos que o fizeram nascer. O paradoxo deste ser reside no facto de ser imanente, isto é, de ser construído pelo coletivo e, ao mesmo tempo, ser transcendente porque é sólido e ultrapassa o coletivo. Graças ao trabalho de tradução, aqui chamado de mediação, o Leviatã absorve um sem fim de objetos. Simultaneamente, o trabalho de purificação esconde a integração de todos esses objetos ao corpo do Leviatã. Uma vez integrados, esses objetos adquirem o estatuto de híbridos e, ainda que tenham poder constitutivo, não se fazem notar. Os modernos não são capazes de des-cobrir este paradoxo, que basicamente impossibilita o autocontrole democrático, porque acreditam que apenas os humanos decidem a direção da sociedade (Latour, 2008, p. 46). 
Podemos tomar o Leviatã, tal como Latour o descreve, como um símbolo do coletivo ocidental. Este grupo é insaciável e continua em busca de novos territórios, naturezas e humanos para ingerir e converter na substância (híbrida) que o constitui. Devido à transcendência do Leviatã, que supera os seus cidadãos, a sua natureza é descontrolada e não desdenha a recorrer a meios violentos para satisfazer a sua necessidade de expansão. A queda do céu oferece um testemunho desta ameaça e apresenta o descontrolado coletivo ocidental a partir de uma perspectiva xamânica yanomami. Os napë não respeitam a terra yanomami e ignoram o perigo que representa a empresa ocidental de exploração incessante. As palavras de Kopenawa concentram-se, como as de Latour, no Ocidente a partir da sua relação com os objetos. Kopenawa chama-os principalmente mercadoria, enquanto que Latour denomina-os híbridos. Embora Kopenawa descreva principalmente a sua própria cultura, as suas palavras também oferecem uma antropologia do mundo ocidental. Para demonstrar essa hipótese, apresento na próxima secção a perspectiva de Kopenawa perante a mobilização ocidental da natureza. Podemos ver que essa prática é exercida pelos dois coletivos, mas em escalas completamente diferentes.

\section{Davi Kopenawa e a mobilização do mundo}

As entidades não-humanas, que os dois coletivos mobilizam para se constituírem, são, em primeiro lugar, muito diferentes em relação de quantidade e, em segundo lugar, em relação às suas qualidades. Os yanomami integram, citando apenas alguns exemplos, seres como os xapiri, adornos de origem animal ou materiais de construção que a selva Ihes fornece (Kopenawa e Albert, 2015, p. 175). Os napë, por outro lado, integram metais (explorados pela exploração mineira), petróleo, gás, ou seja, praticamente qualquer matéria, que depois transforma numa multiplicidade de híbridos que povoam o mundo. Muitas vezes, estes objetos adquirem formas muito ameaçadoras, como é o caso das máquinas de desflorestação, as armas, e todo o tipo de materiais não biodegradáveis. A integração de novas entidades ao coletivo acontece de forma despreocupada no caso dos napë. Os yanomami, por sua vez, alertam-nos para uma integração excessiva. Kopenawa pronuncia-se em variadíssimas situações contra a disseminação de objetos napë nas terras yanomami, pois, segundo ele, os objetos distraem o pensamento e criam uma dependência dos brancos (Kopenawa e Albert, 2015, pp. 226-227). Noutro momento, alerta sobre os múltiplos perigos que os humanos correm ao removerem os metais da terra a que pertencem. Para Kopenawa, Omama não os deixou ao fácil alcance dos humanos porque são muito nocivos (Kopenawa e Albert, 2015, p. 357). 
O coletivo napë em contrapartida, - incapaz de meditar sobre as consequências que os híbridos implicam - removem-nos incessantemente. Kopenawa constata:

Escavando tanto, os brancos vão acabar até arrancando as raízes do céu (...). Então ele vai se romper novamente e seremos aniquilados, até o último. (...) Os brancos não pensam nessas coisas. Se o fizessem, não arrancariam da terra tudo o que podem, sem se preocupar. É para acabar com isso que quero fazer com que eles ouçam as palavras que os xapiri me deram no tempo do sonho (Kopenawa e Albert, 2015, p. 361).

Esta citação sintetiza de forma densa as diferentes concepções sobre a mobilização do mundo. Enquanto os napë extraem os metais, os yanomami temem que o céu caia com essa atividade. As raízes do céu são uma entidade não-humana que os yanomami mobilizam. Para os ocidentais, por outro lado, o céu não tem raízes e a sua queda é uma ideia inexistente, para não dizer absurda.

Apesar de mostrar diferentes graus de mobilização, a citação também se refere ao propósito que Kopenawa persegue no seu texto. Ao contrário das obras de Chagnon, o livro de Kopenawa apresenta uma voz indígena que não se dirige apenas à sua própria sociedade, mas que tenta enviar uma mensagem aos napë. As palavras de Kopenawa foram traduzidas em diferentes línguas e na forma - a escrita - dos napë, para poderem ser percebidas longe do seu lugar de origem. Da mesma forma, as suas palavras têm como objetivo serem amplamente divulgadas e contribuírem para acabar as ideias falsas que circulam em torno dos yanomami (Kopenawa e Albert, 2015, p. 76).

O saber de Kopenawa está baseado no estudo da selva e da cultura yanomami, na sua longa experiência com a cultura ocidental e, sobretudo, numa comunicação xamânica com os espíritos, os xapiri. Segundo Kopenawa, as palavras dos xapiri têm a qualidade de serem verdadeiras, diferindo, portanto, das palavras autorreferenciais que os napë divulgam nos seus livros (Kopenawa e Albert, 2015, p. 76). A partir das ideias de Eduardo Viveiros de Castro, podemos interpretar o texto de Kopenawa como um ato xamânico, pois é possível entender o xamanismo como uma diplomacia cósmica que se dedica a intermediar as diferentes posições ontológicas. O livro apresenta uma intermediação xamânica no sentido em que fala aos napë sobre os espíritos, e também fala a partir dos espíritos sobre os napë. Com a ajuda de Albert, Kopenawa consegue assim construir uma ponte entre os dois mundos normalmente separados: o mundo dos espíritos e o mundo dos napë (De Castro, 2007, pp. 14-15). 
O discurso sobre os napë constitui grande parte de A queda do céu. Isto deve-se a várias circunstâncias: Primeiro, uma antropologia yanomami atual não pode de maneira nenhuma ignorar a cultura ocidental. Os napë invadem o território yanomami incessantemente, trazendo consigo doenças mortais, destruição ambiental e violência (Kopenawa e Albert, 2015, p. 226). Infelizmente, eles ainda representam uma ameaça que já causou muitas mortes e sofrimento. Segundo, $A$ queda do céu é um protesto contra os napë feito por uma voz yanomami informada pelo mundo dos xapiri. Isto quer dizer que Kopenawa não apenas apresenta a riqueza cultural yanomami, mas que também informa o leitor napë dos danos que o coletivo ocidental está a causar.

Em resumo, A queda do céu é ao mesmo tempo uma antropologia dos yanomami e uma antropologia do Ocidente. As referências à cultura napë estão presentes do início ao fim do livro e constituem, deste modo, um estudo yanomami sobre a cultura do Ocidente. Graças ao contacto que Kopenawa teve com os napë - seja pela intrusão destes na selva, pelo trabalho com eles ou ainda pelas múltiplas viagens que fez - o livro reflete um alto conhecimento do coletivo ocidental.

\section{Conclusão}

Este ensaio não só conseguiu dar uma ideia da ameaça que o Ocidente representa para os yanomami, como também apontou algumas das circunstâncias que a fomentam. Uma delas é o discurso que desumaniza os yanomami, reduzindo-os a um outro selvagem e que é usado para legitimar a violência contra eles. Como vimos este discurso alimenta-se de diferentes representações, tais como, para citar alguns exemplos, os trabalhos antropológicos e os relatos estabelecidos sobre o selvagem. A queda do céu ocupa um lugar importantíssimo porque apresenta um contra-relato que revaloriza os yanomami e testemunha da existência de uma cultura antiga e rica. Além disso, esta obra mostrou que o Ocidente se constrói graças a uma incorporação descontrolada do âmbito natural que continuamente amplia o seu coletivo. Este processo, que tentei explicar a partir das ideias de Bruno Latour, é o cerne da cultura ocidental. Ainda que isto possa parecer abstrato, é o pior inimigo dos yanomami porque é a base da invasão incessante das terras indígenas por parte dos napë.

O diálogo entre A queda do céu e Jamais fomos modernos acabou por ser altamente fecundo. Os dois pensadores apresentam as respectivas antropologias do mundo ocidental, cujas leituras paralelas se enriquecem 
mutuamente. Enquanto que Bruno Latour descreve um Leviatã descontrolado, cujo corpo é constituído por uma multiplicidade de híbridos, Davi Kopenawa fala-nos de um Ocidente violento a que chama povo da mercadoria. Ambos os pensadores veem com muita lucidez o perigo que os objetos representam; seja pela obsessão de os possuir, seja pelo total desconhecimento dos seus efeitos sociais e ambientais.

\section{Bibliografia}

Carvalho, J. P. F. de (1982). Waimiri Atroari. A história que ainda não foi contada. Brasilia.

Chagnon, N. (1968). Yanomamö. The fierce people. New York: Holt, Rinehart and Winston.

- (2013). Noble savages. My life among two dangerous tribes - The yanomamö and the anthropologists. New York: Simon and Schuster.

Crutzen, P. J. (2006). "The 'Anthropocene". In Earth System Science in the Anthropocene. Emerging Issues and Problems (pp. 13-18). Berlin: Springer Science \& Business Media.

Danowski, D. e De Castro, E. V. (2014). Há mundo por vir? Ensaio sobre os medos e os fins. São Paulo: Cultura e Barbárie Editora.

De Castro, E. V. (2007). "The Crystal Forest. Notes on the Ontology of Amazonian spirits". In Inner Asia 9, pp. 13-33.

- (2015). "Prefácio - O recado da mata". In D. K. Yanomami e B. Albert, A queda do céu. Palavras de um xamã yanomami (pp. 11-41). São Paulo: Companhia das Letras.
Hobbes, T. (1990). Leviatán o la materia, forma y poder de una república eclesiástica y civil. Valencia: Publicacions de la Universitat de València.

Kopenawa Yanomami, D. e Albert, B. (2015). $A$ queda do céu. Palavras de um xamã yanomami. São Paulo: Companhia das Letras. Latour, B. (1994). Jamais fomos modernos. Ensaio de antropologia simétrica. Rio de Janeiro: Ed. 34.

- (2008). Wir sind nie modern gewesen. Versuch einer symmetrischen Anthropologie. Frankfurt am Main: Suhrkamp.

Lizot, J. (1974). "Histoires indiennes d'amour". Les Temps Modernes 339, 1-34.

Luhmann, N. (1997). "Weltgesellschaft". In N. Luhmann. Die Gesellschaft der Gesellschaft (pp. 145-170).Frankfurt am Main: Suhrkamp,

White, H. (1978). "The Forms of Wildness. Archeology of an Idea". In H. White, Tropics of Discourse. Essays in Cultural Criticism (pp. 150-182). Baltimore: Johns Hopkins University Press. 